\title{
Organizational Learning Supported by Reference Architecture Models: Industry 4.0 Laboratory Study
}

\author{
Marco Nardello $^{1 *}$, Charles Møller $^{1}$ and John Gøtze ${ }^{2,3}$ \\ ${ }^{1}$ Aalborg University, Department of Materials and Production, Fibigerstræde 16, \\ DK-9220 Aalborg East, Denmark \\ ${ }^{2}$ IT University of Copenhagen, Rued Langgaards Vej 7, DK-2300 Copenhagen, \\ Denmark \\ ${ }^{3}$ QualiWare aps, Ryttermarken 15, 3520 Farum, Denmark \\ man@mp.aau.dk, charles@mp.aau.dk, jogo@itu.dk
}

\begin{abstract}
The wave of the fourth industrial revolution (Industry 4.0) is bringing a new vision of the manufacturing industry. In manufacturing, one of the buzzwords of the moment is "Smart production". Smart production involves manufacturing equipment with many sensors that can generate and transmit large amounts of data. These data and information from manufacturing operations are however not shared in the organization. Therefore the organization is not using them to learn and improve their operations. To address this problem, the authors implemented in an Industry 4.0 laboratory an instance of an emerging technical standard specific for the manufacturing industry. Global manufacturing experts consider the Reference Architecture Model Industry 4.0 (RAMI4.0) as one of the corner stones for the implementation of Industry 4.0. The instantiation contributed to organizational learning in the laboratory by collecting and sharing up-to-date information concerning manufacturing equipment. This article discusses and generalizes the experience and outlines future research directions.

Keywords: Digital Manufacturing, RAMI 4.0, Enterprise Architecture, Smart Production, Organisational Learning.
\end{abstract}

\section{Introduction}

"The fundamental purpose of Industry 4.0 is to facilitate cooperation and collaboration between technical objects" [1]. The novelty introduced by Industry 4.0 is the communication capability of new products and new production equipment. German public and private institutions developed the Reference Architecture Model Industry 4.0 (RAMI4.0) that provides a common vocabulary and structure to describe Smart Production (Industry 4.0 components). In March 2017, the

\footnotetext{
* Corresponding author

(C) 2017 Marco Nardello et al. This is an open access article licensed under the Creative Commons Attribution License (http://creativecommons.org/licenses/by/4.0).

Reference: M. Nardello, Ch. Møller and J. Gøtze, “Organizational Learning Supported by Reference Architecture Models: Industry 4.0 Laboratory Study,” Complex Systems Informatics and Modeling Quarterly, CSIMQ, Issue no. 12, pp. $22-38,2017$. Available: https://doi.org/10.7250/csimq.2017-12.02

Additional information. Author's ORCID iD: M. Nardello - orcid.org/0000-0003-0387-0047, Ch. Møller - orcid.org/0000-00030251-3419 and J. Gøtze - orcid.org/0000-0003-3517-6180. Article PII S225599221700069X. Article received: 2017 September 7. Last revision received: 2017 October 19. Accepted: 2017 October 20. Available online: 2017 October 31.
} 
International Electrotechnical Commission (IEC) adopted RAMI4.0 as a Publicly Available Specification for Smart manufacturing (IEC PAS 63088:2017).

From informal interviews, the authors acknowledged that Danish manufacturing companies are underutilizing the Industry 4.0 components. In fact, the data and information generated during manufacturing operations is usually stored but it is not shared or used in the organization. This impedes organizational learning to take place preventing the organization to improve their manufacturing operations.

Organizational learning is intended as "the process by which new knowledge or insights are developed by a firm" [2]. It is divided in four consecutive sub processes: information acquisition, information dissemination, shared interpretation, and development of organizational memory [3]. From the authors' understanding, most of the Danish manufacturing companies fail at the information dissemination, therefore blocking the organizational learning process. The goal of this study is to develop a solution by applying a standard framework to enable information dissemination and therefore allow the organizational learning process to progress. The authors chose RAMI4.0 because of its importance in the manufacturing industry ${ }^{\dagger}$. This work is an extension of the authors previous work [4]. The research questions studied in this article are:

1. How is RAMI4.0 instantiated?

2. How does an instantiation of RAMI4.0 contribute to organizational learning?

3. How does an instantiation of RAMI4.0 contribute to the information dissemination sub process?

To assess these research questions, the authors conducted a study where they modelled the Smart Production Laboratory ("Lab" in the remaining of the article) at Aalborg University using RAMI4.0. This Lab includes fully automated conveyor belt modules with mounted on top manufacturing equipment. In addition to contributing to organizational learning, the authors are presenting in this article the first instantiation of this reference architecture model. At the time of writing, to the authors' knowledge no application of RAMI4.0 was published in journals or conference proceedings. Therefore, this article is the first to demonstrate its application. Related work includes, Langmann et al. in [5] modelled a manufacturing equipment as an Industry 4.0 component, and Pauker et al. in [6] presented an approach for information model design in Industry 4.0 .

The authors developed the instantiation applying design-science based research methodology. The results of the application of the reference architecture model show that it contributes to organizational learning by collecting knowledge related to manufacturing equipment and by providing up-to-date and exhaustive information about it.

This article continues with a description of the reference architecture model and organizational learning literature in Section 2. Afterwards, the authors describe the methodology and the laboratory. In Section 4, the artifact is presented. The article concludes with the findings in Section 5, the discussion in Section 6 and the conclusion in Section 7.

\section{Background}

This section starts with a description of the reference architecture model, its three dimensions and the structure of each dimension. Afterwards, it presents background knowledge on organizational learning.

\footnotetext{
${ }^{\dagger}$ https://www.zvei.org/en/subjects/industry-4-0/the-reference-architectural-model-rami-40-and-the-industrie-40-component/ http://blog.iiconsortium.org/2016/03/the-industrial-internet-is-important-new-technologies-and-new-business-opportunities-willdisrupt-industries-on-many-level.html
} 


\subsection{Reference Architecture Model Industry 4.0}

RAMI4.0 provides a structure for describing different aspects of an asset [1]. An asset is defined as an "object which has a value for an organization" [1], which therefore not only means physically tangible objects, but also intangible objects such as ideas, archives and software. An asset is not necessarily an I4.0 component: "only if it is an entity, has at least passive communication capability and has been equipped with an 'administration shell' does an asset become an I4.0 component" [1]. One of the goals of this reference architecture model is to facilitate the understanding of an asset by analyzing it using three dimensions, as shown in Figure 1: (1) architecture axis, (2) life cycle and value stream, and (3) hierarchy levels. This approach aims at reducing the complexity of analysis of an asset to more manageable units and at the same time provide a holistic view of it by establishing relations between these dimensions.

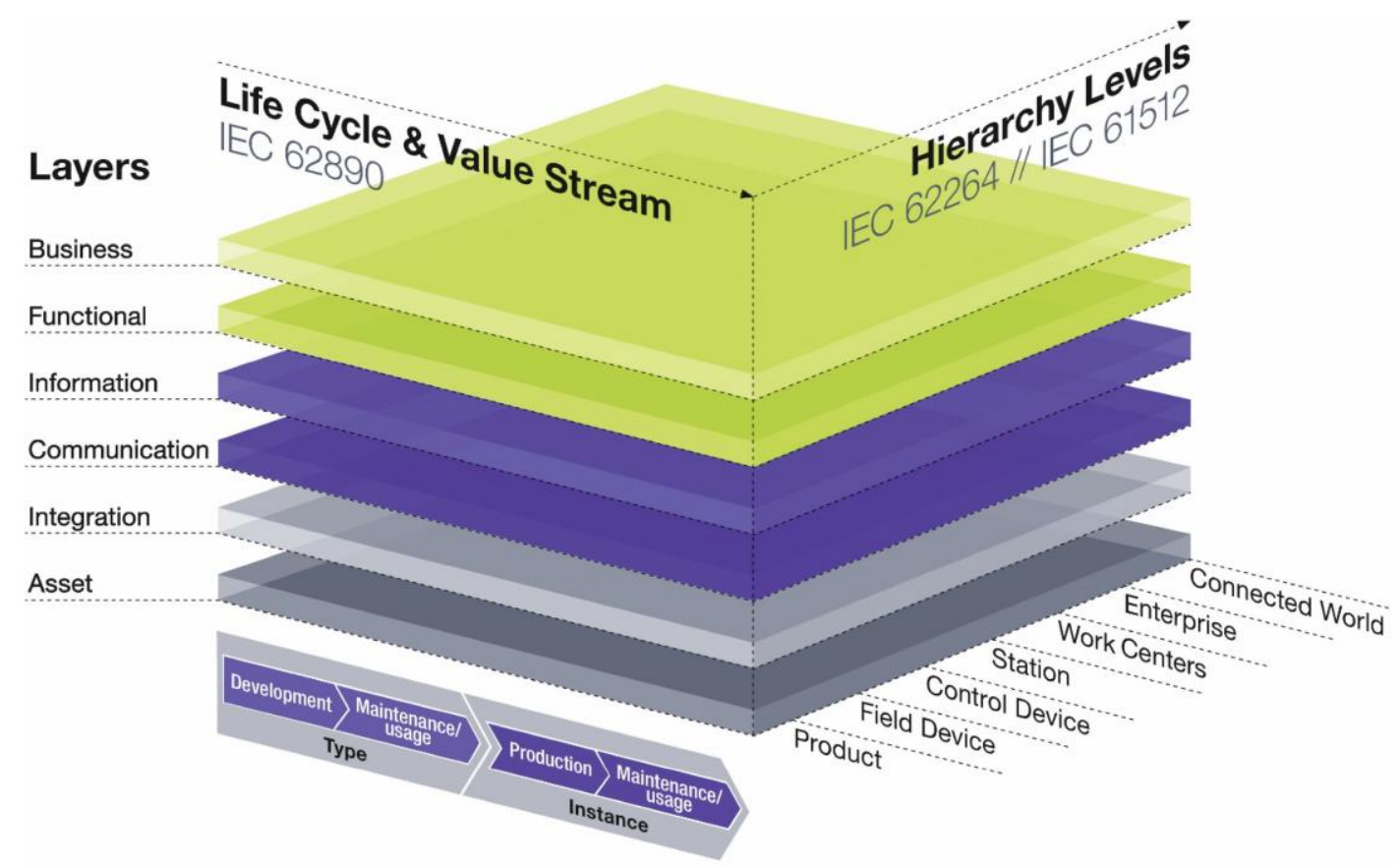

Figure 1. Reference architecture model Industry 4.0 (RAMI4.0) [1]

First, the architecture axis dimension structures the asset's properties and functions specifying its relation to the different aspects. In RAMI4.0 these aspects are organized in six layers [1]:

- The business layer describes the commercial view of an asset and it includes several business concepts. Starting with organizational boundary conditions (such as order commissioning and general ordering conditions), monetary conditions (price, availability of resources, discounts), and legal and regulatory conditions. This layer includes also business models, business processes, service orchestration and their relationship.

- The functional layer describes the logical and technical functions of an asset by providing a digital description of its functions and a platform for horizontal integration among assets' functions. In addition, it includes models with runtime data of processes, functions and applications.

- The information layer describes the data related to the technical functionality of an asset. These data are divided between non-real-time data (like execution rules, data integration rules, and interfaces for structured data transmission) and real-time data (like production data and events that impact the functional layer).

- The communication layer describes "the access to information and functions of a connected asset by other assets" [1]. This layer specifies "which data is used, where it is used and when it is distributed" [1]. Communication between assets requires the use of a uniform data format 
among the different assets combined with a "data publishing services" to make the data available. The publishing service is a core concept of Service-Oriented Architecture (SOA).

- The integration layer documents the relation from the physical world to the information world. Changes in the physical world need to be represented in the information world. It includes the infrastructure (e.g. field buses, RFID and QR codes) necessary to implement a function, as well as the properties and process-related functions required to use an asset in the intended way.

- The asset layer digitally represents physical assets, for instance a production equipment or a product. For every asset represented in this layer there must be a virtual representation in the above layers. Among the physical assets, this layer includes the digital interface with humans and the relationship to elements in the integration layer (e.g. Sensor ID).

The second dimension is the life cycle and value stream dimension and it is based on the IEC 62890 standard [7] - Life-cycle management for systems and products used in industrial-process measurement, control and automation - which is under development at expected to be published in 2018. The draft standard makes a clear distinction between product type and product instance. The product type information relates to the asset's characteristics that are common to all types of that asset (e.g. product part ID) and pertaining documentation (e.g. design documents, assembly instructions, technical documentation, certificates, and so on). The product instance information relates to the properties of an individual instance of that type of asset (e.g. product serial number) and data pertaining to that instance (e.g. manufacturing data, life time data, and so on). In RAMI4.0, this distinction is used to structure the life-cycle model, shown in Figure 2. Starting with the life-cycle for the product type, an asset life-cycle has four phases - development, sales, after-sale support, obsolete - and three milestones at the end of the first three phases - sales release, end of sales, end of service. The product instance life-cycle is specific for each product instance and has two processes - manufacturing and standard service. The manufacturing process starts when the product type has been developed and the delivery release milestone is reached. This process continues until the end of production milestone is achieved. Like the manufacturing process, the standard service process begins when the delivery release milestone is reached and it continues until the product is abandoned.

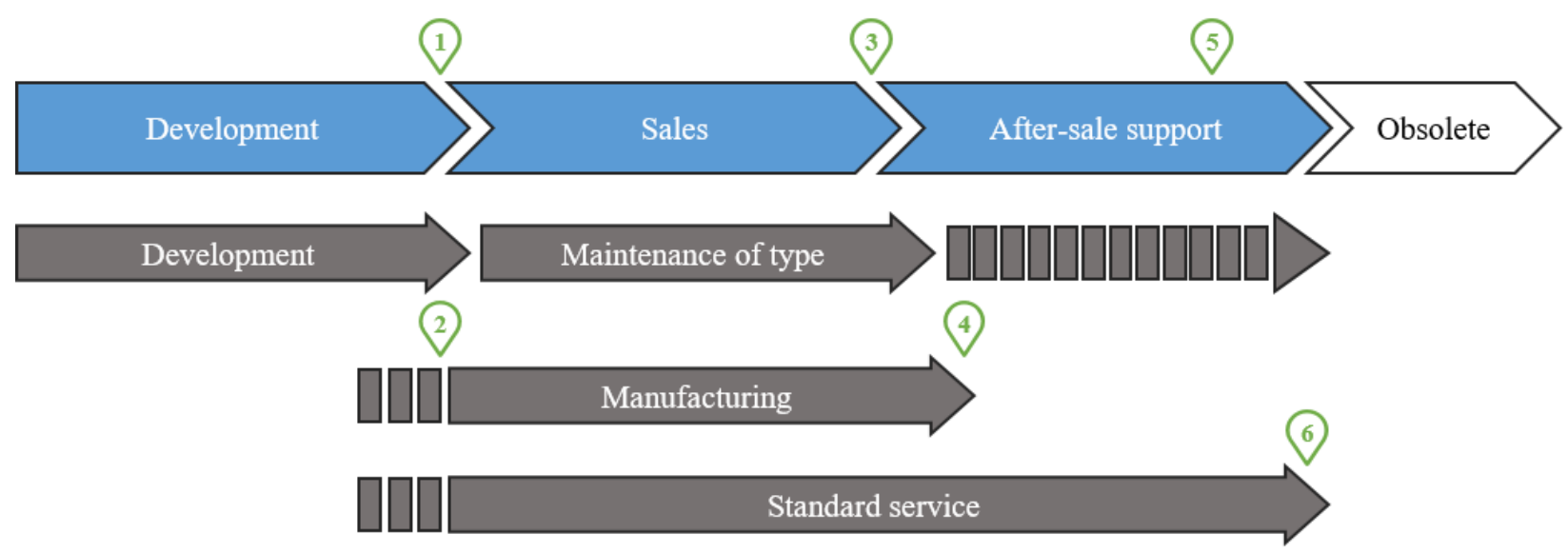

Sales release

Delivery release
End of sales

End of production
End of service

Product abandonment

Figure 2. Generic life-cycle model adapted from [7] 
The third dimension is the "Hierarchy levels" axis and is meant to assign functional models to specific hierarchy levels, as shown in Figure 3. It is based on the IEC 62264-1 and IEC 61512-1 standards, also known as the ISA-95 hierarchy, which define boundaries between the enterprise systems and the control systems (ERP and MES). Architecturally, the hierarchy levels represent a rather orthodox approach based on the 1991 Purdue Enterprise Reference Architecture [8]. It should also be noted that IEC 61512-1 has not been updated since the 1997-version. Starting from the lower levels, the product and field device levels represent the information required to perform the manufacturing activity. Abstracting from the production activity, the control device, station, work centres and enterprise levels identify the asset's information related to different levels in the enterprise. The final level is the connected world level which is the most extended level. It identifies the information related to an asset that is meant to be shared between different enterprises (or companies).

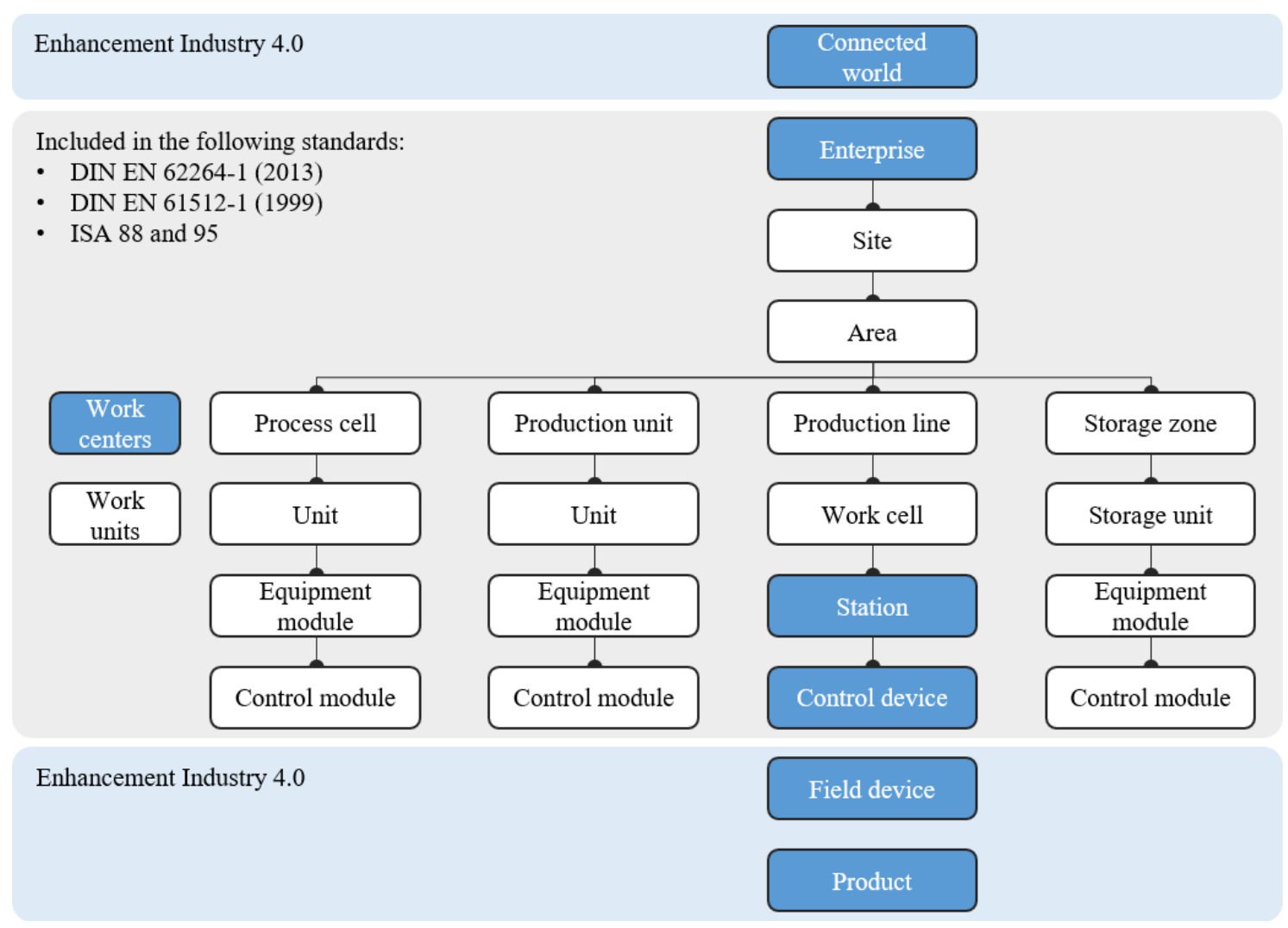

Figure 3. Hierarchical levels of RAMI4.0 adapted from [1]

RAMI4.0 describes "a reference architecture model in the form of a cubic layer model, which shows technical objects (assets) in the form of layers, and allows them to be described, tracked over their entire lifetime (or "vita") and assigned to technical and/or organizational hierarchies" [1]. It also describes "the structure and function of Industry 4.0 components as essential parts of the virtual representation of assets" [1].

The fact that this reference architecture model is a PAS (Publicly Available Specification; IEC PAS 63088:2017) means that it has become available with IEC logo via IECs webshop, but also that it is not a "real" IEC standard. Importantly, it makes both direct and normative references to a number of other IEC standards. As mentioned, this reference architecture model directly uses IEC 62264-1, IEC 61512-1, and IEC 62890; one established standard, one outdated standard, and one emerging but unproven standard. In terms of the instantiation, the authors have focused on making the artifact support RAMI4.0 as an idea, or a framework, more than implementing it "by the letter" since compliance is not the main purpose of this article. 


\subsection{Organizational Learning}

The organizational learning field comprises several academic and professional disciplines, most notably the learning organization [9], organizational knowledge creation [10], double-loop learning [11], and situated learning [12]. Brown and Duguid in [13] established that learning is a social process, and Wenger in [14] developed a theory of social learning based on communities of practice, which are defined as "a group of people informally bound together by shared expertise and passion for a joint enterprise" [15]. Communities of practice can be thought of as "shared histories of learning", and they "record their memory" through complex processes of participation and reification [14].

At its most basic level, organizational learning is "the process by which new knowledge or insights are developed by a firm" [2]. In organizational learning literature, this process is generally perceived as four sub processes [3]: information acquisition, information dissemination, shared interpretation, and development of organizational memory.

First, the information acquisition process allows an organization to actively look for and gather useable information [2]. For this sub process there are three distinct sources [3]: direct experience, experience of others, and organization's own memory mechanisms. Once information is acquired by the organization, through the information dissemination process it is "distributed to those individuals who need it in order for the learning process to be effective" [2]. After the information is disseminated, consensus as to the meaning of the information evolves in the organization [2]. This process, known as the shared interpretation process, refers to the presence of consensus among organizational members with regard to the meaning of information [3]. Finally, the organizational memory process "refers to the amount of stored information or experience an organization has about a particular phenomenon" [16]. This last process provides first "a foundation for change through generative learning processes, and second, it can have a significant impact on the learning process by influencing the type of information that is sought and the manner in which the information is analysed" [3].

In this article the authors present an innovative use of reference models to support organizational learning. Few papers applied reference or architectural models to support the organizational learning or knowledge sharing. One of them is [17] where the authors developed a distributed knowledge management framework to improve learning and cooperation capabilities. Through the application of RAMI4.0 the authors intend to demonstrate the contribution of reference models to organizational learning.

\section{Methodology}

In this study, the authors applied design-science research methodology for information systems [18] because they created and evaluated new IT artifacts. The four main steps of this study were [19]: problem identification, definition of objectives of the artifact, design and development of the artifact, and evaluation of the artifact. The authors demonstrated in a laboratory the solution's contribution to the organizational learning field and collected feedback for further development. During the first and the last steps, the Lab manager was involved because of his unique knowledge on the Lab activities.

\subsection{Problem Identification}

To identify the specific research problem, the first author interviewed the Lab manager to understand the challenges and problems affecting students and researchers involved in the Lab.

Based on this interview, the authors decided to investigate two problems experienced also by Danish manufacturing companies related to the information dissemination sub process. The first one was the lack of shared access to information about the production line (e.g. modules errors). This problem is related to the information dissemination process because the information 
generated by the modules of the production line was accessible only locally through the Manufacturing Execution System (MES).

The second problem involved the new knowledge created by the students and researchers - in the form of tutorials, student reports, guidelines and so on - which was either not shared or was shared during biweekly student meetings. As the manager explained, "the only way somebody would know that it [the documentation] exists is by coming to this biweekly meeting where hopefully they [a student group] can say we plan to do something like this and he [a student from another group] can say I actually did it [I will send you my last semester report]". This problem also relates to the information dissemination process because information was disseminated in an unstructured way.

\subsection{Definition of the Objectives of the Artifact}

The problems were addressed with two solutions that were included in the instantiation of the reference architecture model. The authors distinguished between dissemination of machine generated information versus dissemination of human generated information. To address the first problem, solution 1 should enable the communication of self-generated information of the production systems (e.g. error information) to those individuals who needed it (e.g. Lab manager). To address the second problem, solution 2 should enable the communication of human generated information (e.g. tutorials made by a student) to those individuals who needed it (e.g. student group).

\subsection{Design and Development of the Artifact}

The authors designed the artifact modelling the Lab applying RAMI4.0 based on the standard specifications [1] summarized above. QualiWare Enterprise Architecture Platform [20] was used since it provides an extensive set of modelling features that facilitate the modelling of the different elements in the Lab. When modelling, the authors adopted both top-down and bottomup approaches [21]. These approaches are used in SOA modelling so that high-level business aspects are modelled while capturing also low-level aspects, and the relation between the highand low-level elements [21]. The top-down approach consisted in modelling first the business and functional layers of the reference architecture model. When applying the bottom-up approach, the authors started by modelling the asset, integration and communication layers. After several iterations of the two approaches, the authors completed the models required to instantiate RAMI4.0.

\subsection{Smart Production Laboratory}

The authors developed their artifact and demonstrate their value at Aalborg University's Smart Production Laboratory. This research facility is a Learning Factory [22] and it includes a fully automated small production line (Figure 4a) integrating and demonstrating various Industry 4.0 concepts and technologies. Among the different equipment and technologies installed in the Lab (e.g. drones and laser welding robots), the FESTO CP factory and the process modules are the ones relevant for this study. The FESTO CP factory are transportation modules (linear conveyor belts) that form a small modular and expandable factory with Industry 4.0 technologies. These modules are connected to the MES, the system managing the production process, and to a data storing cloud platform. On top of the linear conveyor belt there are the process modules, for instance drilling module, inspection module, and assembly module. These modules are performing the manufacturing activities on the products.

The Lab produces a simplified mobile phone (see Figure $4 \mathrm{~b}$ ) that is transported by the conveyor belt using a carrier (see Figure 4c). This phone is composed of four parts: back-cover, top-cover, circuit board, and fuses. The back and top covers are the structural elements of the 
phone and are made of plastic. The circuit board is a green plastic component with a small structure for holding two fuses.

Among the different production activities in the Lab, the authors modelled in detail the backcover drilling activity and all the related assets and information.

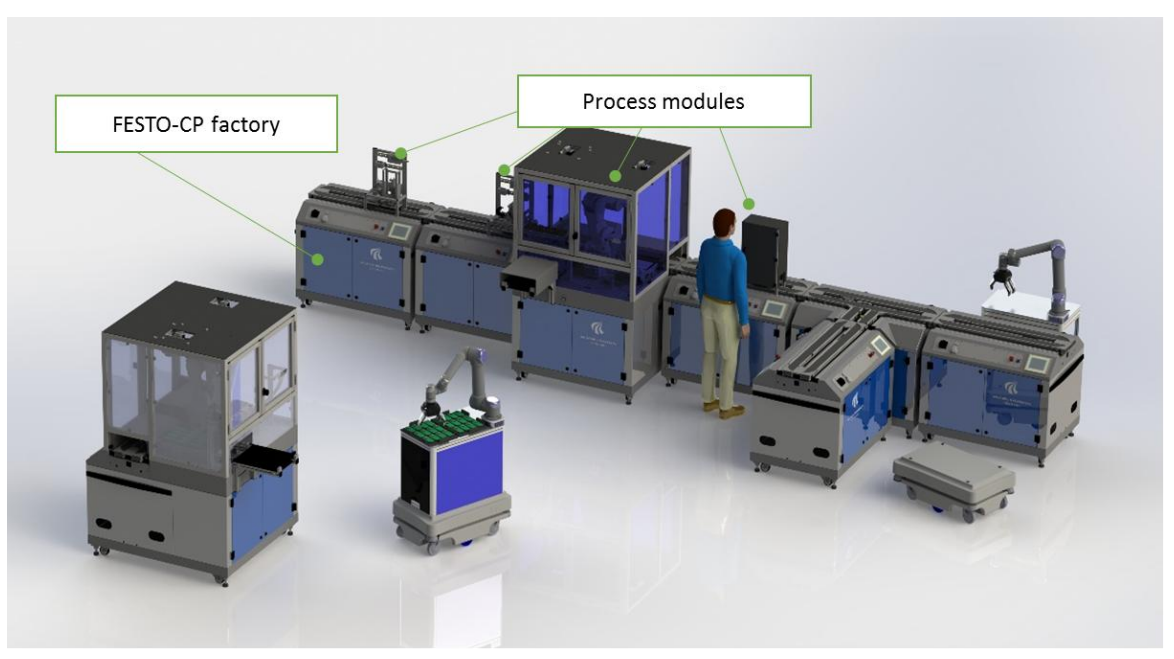

a. Smart Production Laboratory

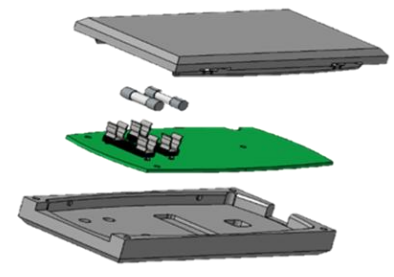

b. Phone

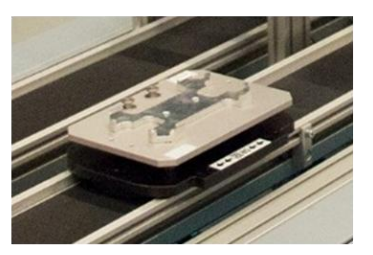

c. Carrier

Figure 4. Overview of the Smart Production Lab

\subsection{Evaluation of the Artifact}

In the last phase of this study, the authors investigated whether the artifact had contributed to the whole organizational learning process and solved the two problems related to the information dissemination sub process. In a second meeting with the Lab manager, the first author presented the instantiation of the reference architecture model. All the models and solutions were shown to the manager. Afterwards to evaluate the artifact, the first author interviewed the manager using an interview guide with open-ended questions. It was divided into five sections: one for each of the four sub processes of organizational learning and a final one about the organizational learning process. For assessing the success of the artifact, the authors analysed the interview transcript identifying relevant quotes from the manager.

At the time of writing, the authors completed one iteration of the design-research methodology. The artifact designed is presented in the next section.

\section{Artifact}

The authors developed as artifact an instantiation of RAMI4.0. For each layer of the reference architecture model, the authors designed at least one model of the layer's architecture which connected to the life cycle and value stream and hierarchical levels dimensions. Based on these models, the authors developed specific features for the two solutions. The first solution focused on the development of the functionalities in the QualiWare platform required to include close to real-time production data from the MES in the models. The second solution used existing functionalities of the platform to link external documents to the models.

In this study, the Lab is the joint enterprise for researchers, students and industry partners working with Industry 4.0. As a research facility for smart production, the Lab is literally a Learning Factory [22]. By introducing the artifact, the authors wanted to demonstrate and analyse reification and participation in the Lab community of practice. By using RAMI4.0 to frame the artifact's "thingness", the authors visualized it as shown in Figure 5. 
This visualization is used in the artifact as an overview screen where all elements are clickable and have links to the models. On the right side of Figure 5, the authors included the definition of each layer of the reference architecture model.

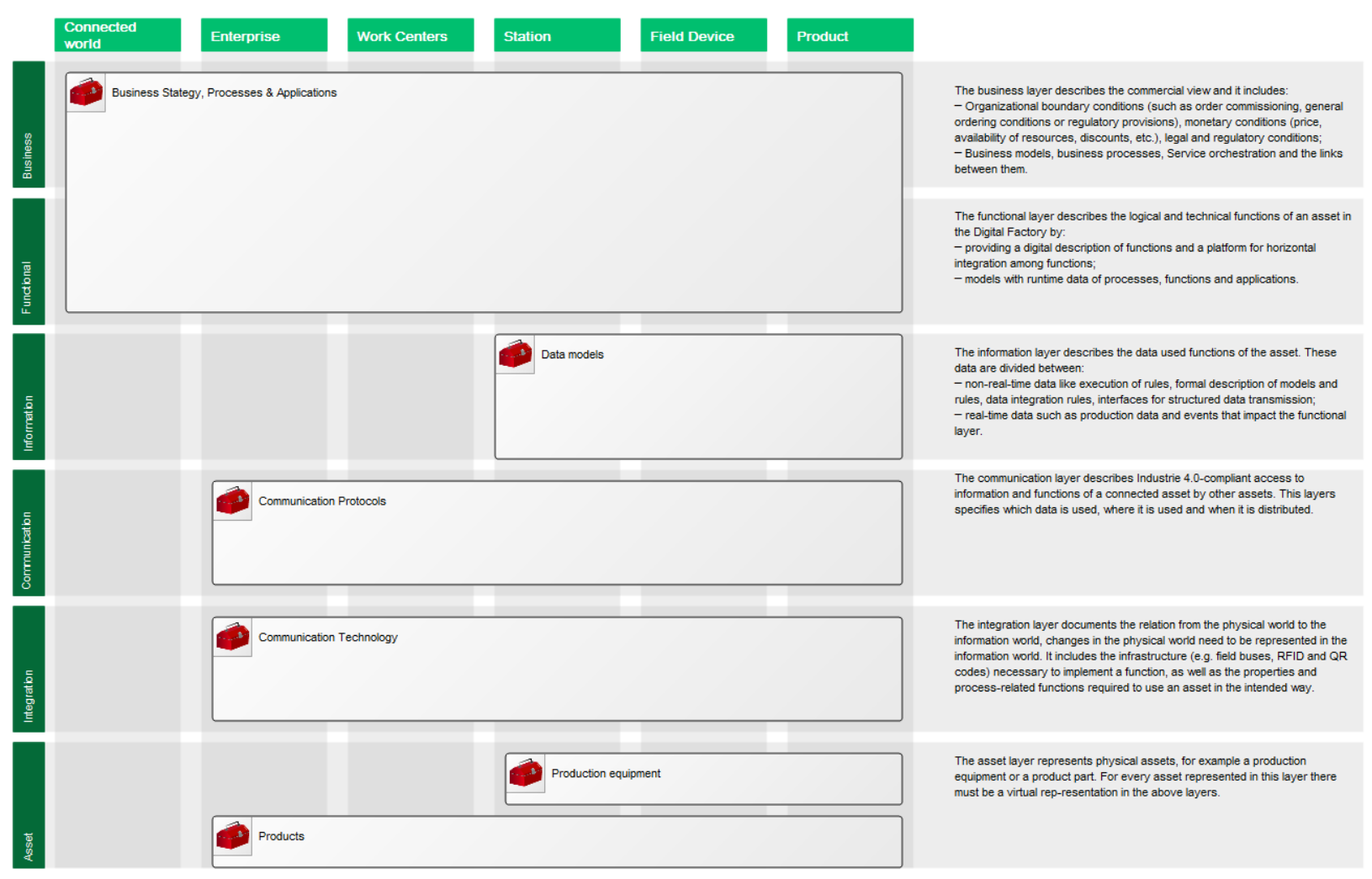

Figure 5. RAMI4.0 framework instantiation

\subsection{Application of RAMI4.0 at Aalborg University Smart Production Lab}

This subsection starts with a description of the models created for each layer of the reference architecture model. It concludes with a more detailed presentation of the process model that was the key for solving the two problems.

The information related to the business layer (Figure 6) is represented in a strategic model which includes different business aspects. The business goal of producing phones is linked to the capability of producing standard phones. The latter is linked to the production process for producing phones. Related to the production process, the model presents also Key Performance Indicators (KPIs) of the production quality and the applications involved. QualiWare Platform could show the values of the KPIs but this aspect was outside the scope of this study.

Information pertaining to the functional layer (Figure 7) is represented in a process model. This model includes the flow of activities, the equipment and the product parts required to produce a phone. Focusing on the drilling activity, a back-cover on a carrier is the input for the activity that produces as output a back-cover with holes on a carrier. This activity is performed at the drilling station, which is composed of one FESTO PLC (Programmable Logic Controller) and one drilling device. This model distinguishes between life cycle and value stream dimensions. What was described above refers to general activity of drilling, while specific drilling data from the equipment in the Lab is available in tables in QualiWare Platform that are accessible by clicking on the drilling activity box (Figure 13).

The information layer (Figure 8) focuses on the data related to assets. A data model diagram represents for each physical asset - back-cover, product, carrier, PLC, drilling equipment - its parameters and attributes in individual classes. The information required for drilling the holes on a back cover are the number of holes and the coordinates of holes. The data flow between assets 
is the following: the information of the number and coordinates of the holes is related from the back cover class to the product class using the part ID attribute of the back cover class and the back cover ID attribute of the product class; all the product information are then accessible by the PLC through the carrier ID attribute of the carrier class which links back to the product ID attribute of the product class.

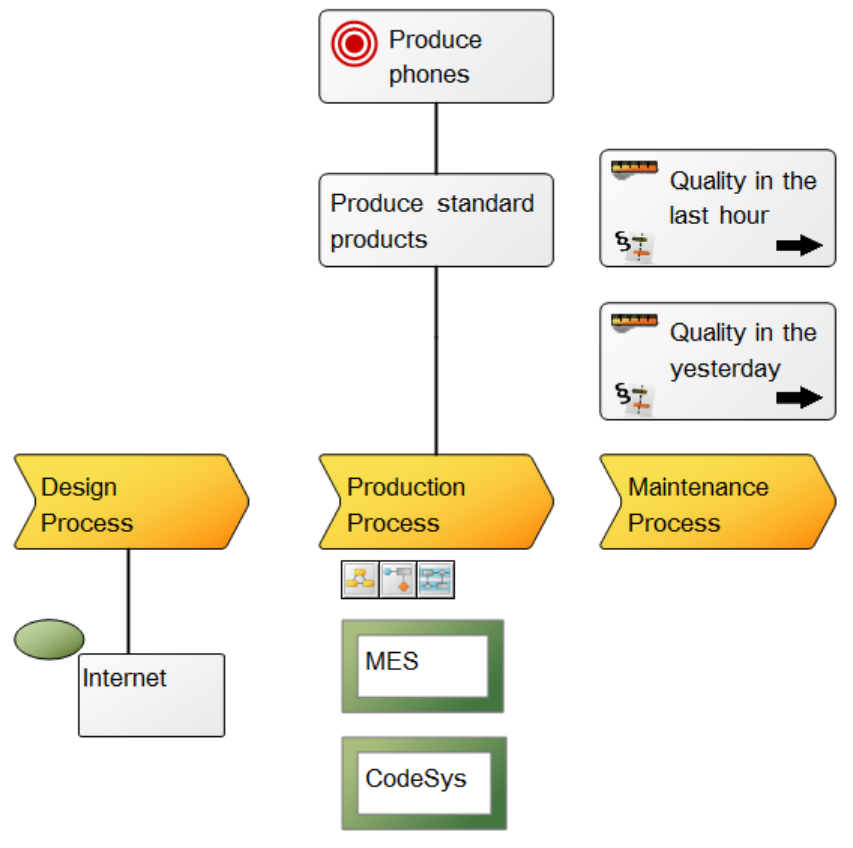

Figure 6. Business layer

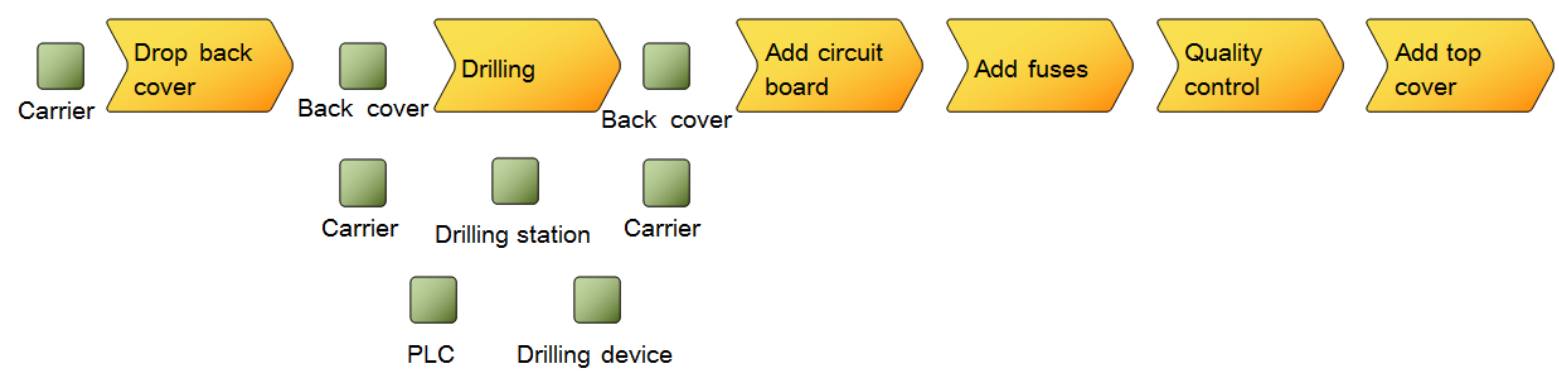

Figure 7. Functional layer

The content of the communication layer (Figure 9) is presented in an application model. Within the context of the drilling process, the application model describes the interaction between the MES system and the PLC application of the drilling station and the message flow. An example of communication between applications is the following: (1) the drill holes PLC informs the MES system that a carrier is at its station, (2) the MES system instructs the PLC about which activities to perform (e.g. let the carrier through, drill 2 holes, or drill 4 holes), and (3) the PLC informs the MES system it has completed the activity.

Continuing with the integration layer (Figure 10), the physical interaction between the carrier and the PLC is documented through an infrastructure and communication model. When a carrier reaches a PLC station, the carrier RFID transmitter communicates the carrier ID to the PLC RFID reader.

Finally, information about the asset layer (Figure 11) is presented in a product model and an equipment model. In the first model, the phone and its parts and the related characteristics are 
specified (e.g. the top cover can be black, white, or blue). The modelling object representing the phone (named "Phone dummy" in the model, see Figure 11) is linked to the elements in the other layers. In detail, the phone is linked to the "produce phone" goal, "producing standard phones" capability, "production process" elements in business and functional layer. Moreover, the phone is also linked to the "product" class in the information layer.

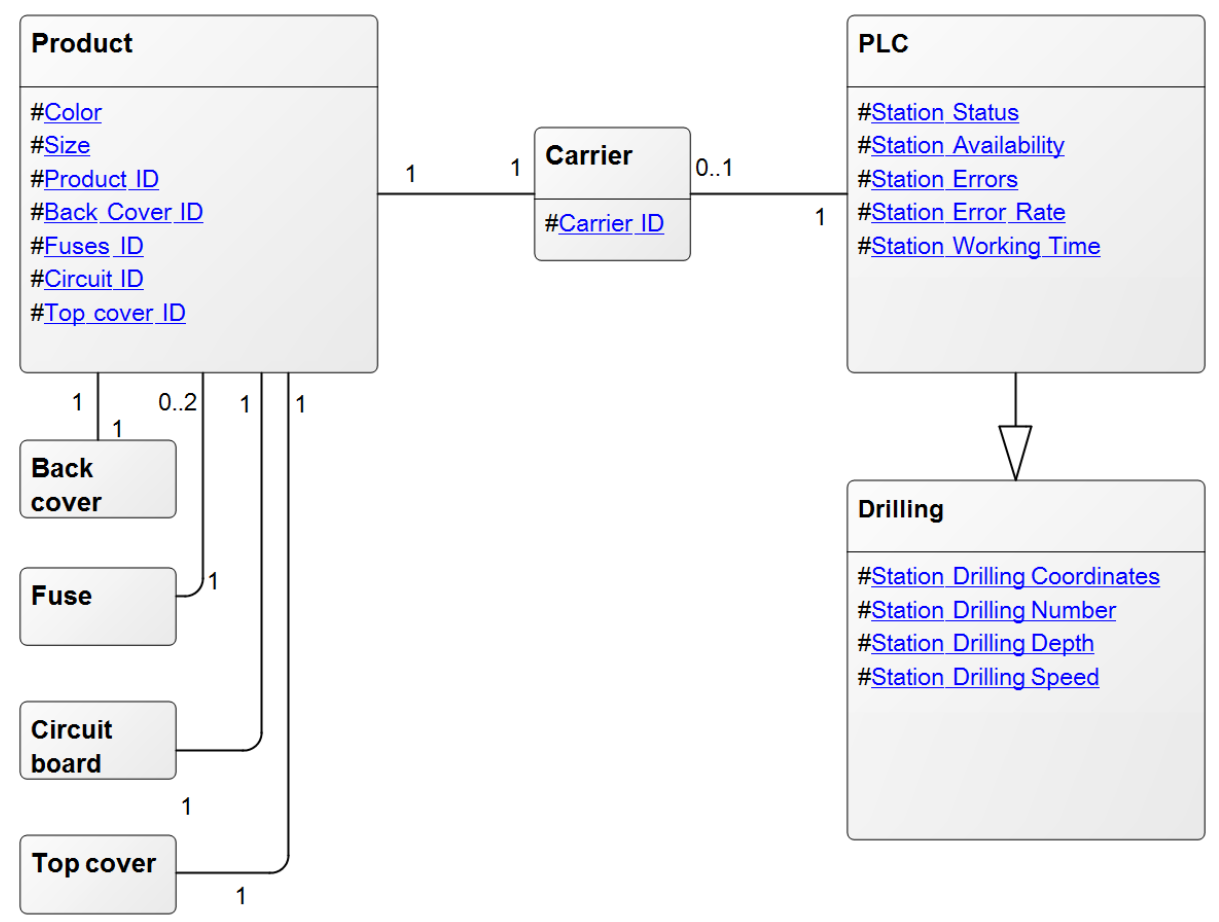

Figure 8. Information layer

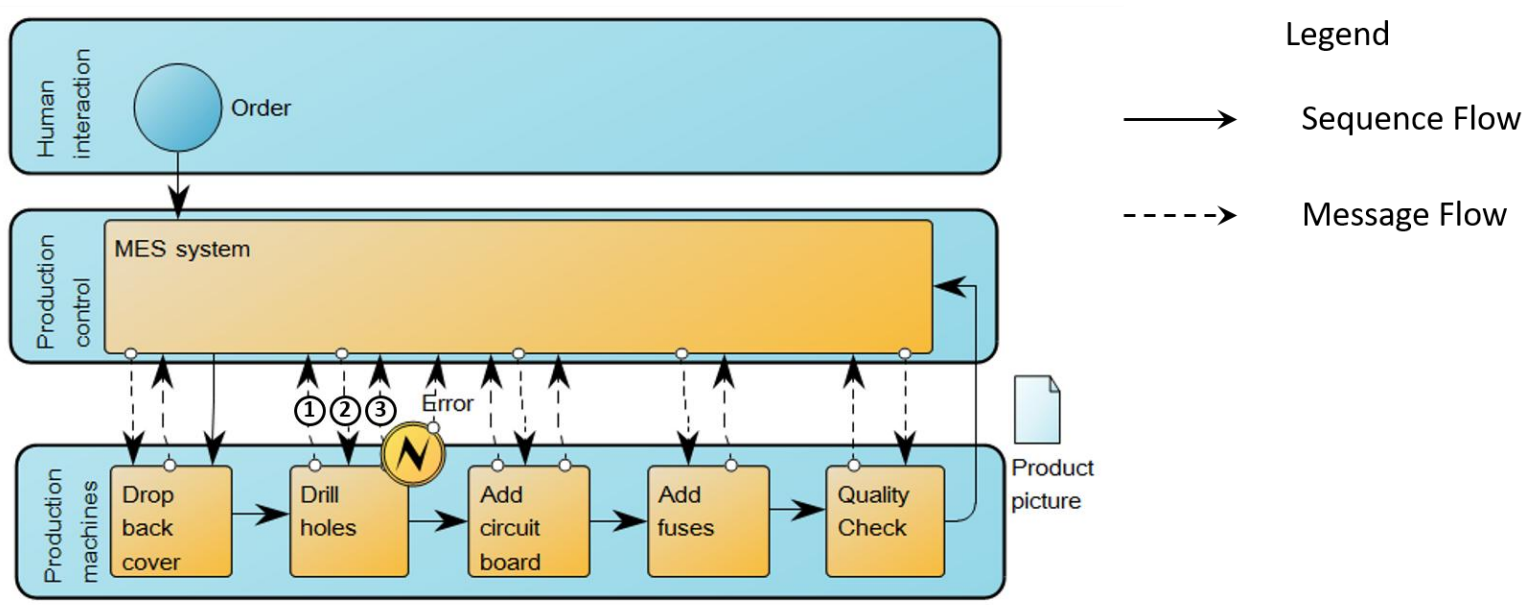

Figure 9. Communication layer 


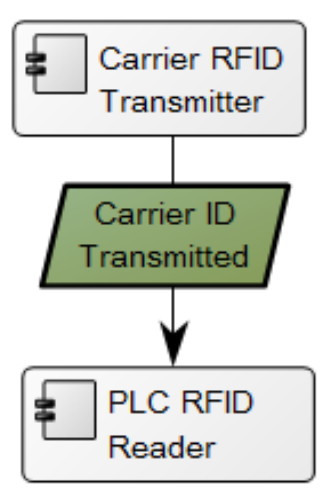

Figure 10. Integration layer

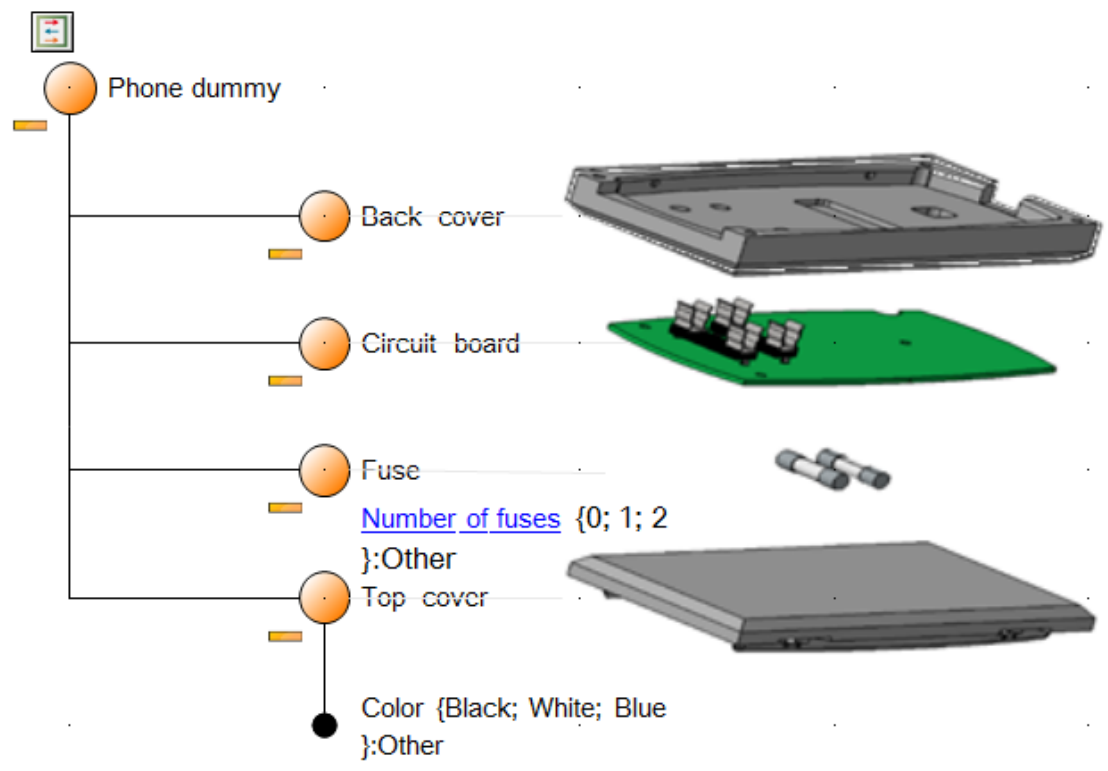

Figure 11. Asset layer, product model

The model of the drilling equipment represents the asset and its sensors as shown in Figure 12 . In this way it is possible, for instance, to specify which physical actuators are responsible for the drilling coordinates and which - for the drilling activity.

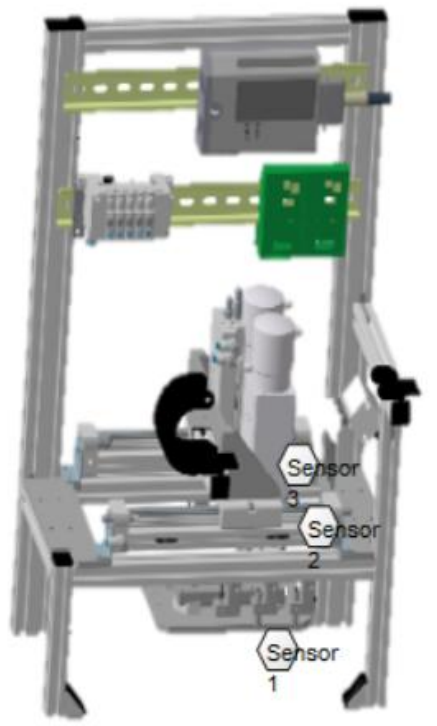

Figure 12. Asset layer, equipment model 


\subsection{Solution 1 - Self-generated Information}

The first solution focused on the drilling activity and it required the creation of three new elements in the QualiWare platform that involved an integration with the MES: a modified version of the production process model (Figure 13b), one table with the last 10 products manufactured (Figure 13c), and one table with the last ten errors (Figure 13d). The production process model was modified by highlighting in red the activity and the equipment with an error. The tables contained simulated data. For the last ten parts produced by a module, the table shows the order number, the product ID, the time stamp, when the activity started and ended (the last two columns are not represented in the figure due to space constrains). For the last ten errors, the table specifies the Error ID (e.g. emergency stop button being pressed or loss of connection between the module and the MES system), the last product ID elaborated by the module and the time stamp. All these models were linked to the drilling activity in the production process model.
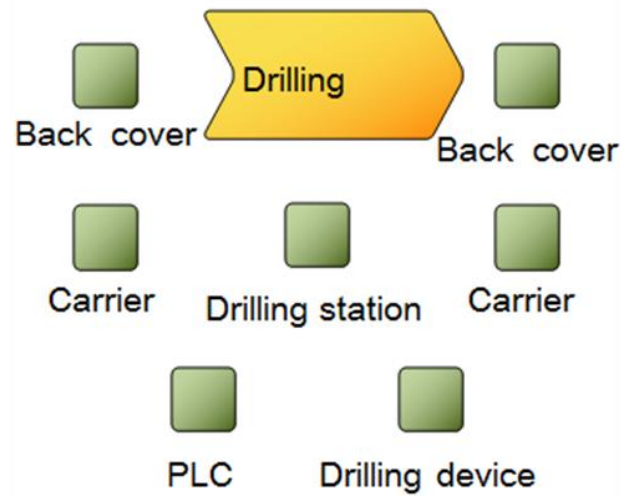

a. Production process without errors

\begin{tabular}{|c|c|c|c|}
\hline Drilling & Order number & Order & Timestamp \\
\hline 1 & 2756 & 1211 Product no fuse & $2017-04-24 \mathrm{~T} 13: 42: 24.2701810 \mathrm{Z}$ \\
\hline 2 & 2755 & 1212 Product fuse left & 2017-04-24T13:42:04.3009428Z \\
\hline 3 & 2755 & 1212 Product fuse left & 2017-04-24T13:42:05.0097208Z \\
\hline 4 & 2755 & 1212 Product fuse left & 2017-04-24T13:42:06.0699465Z \\
\hline 5 & 2754 & 1213 Product fuse right & 2017-04-24T13:42:03.2559943Z \\
\hline 6 & 2753 & 1211 Product no fuse & 2017-04-24T13:41:54.6500661Z \\
\hline 7 & 2753 & 1211 Product no fuse & 2017-04-24T13:41:55.6804606Z \\
\hline 8 & 2753 & 1211 Product no fuse & $2017-04-24 \mathrm{~T} 13: 41: 56.7563202 \mathrm{Z}$ \\
\hline 9 & 2753 & 1211 Product no fuse & 2017-04-24T13:41:57.8364206Z \\
\hline 10 & 2753 & 1211 Product no fuse & 2017-04-24T13:41:58.9220966Z \\
\hline
\end{tabular}

c. Last production
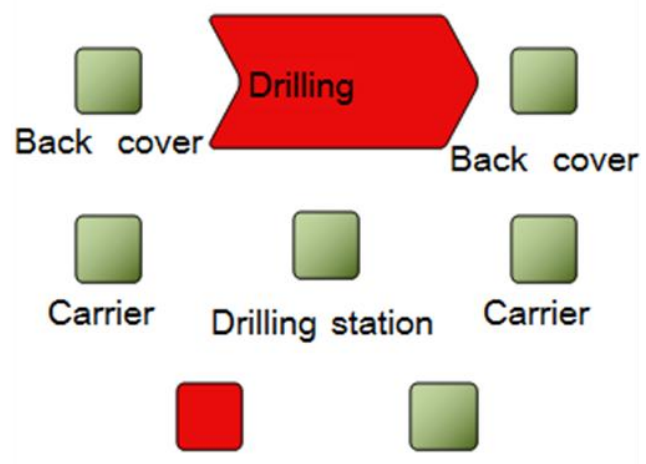

PLC Drilling device

b. Production process with errors

\begin{tabular}{|l|l|ll|}
\hline Dillin & Error ID & Product ID & \multicolumn{1}{c|}{ Timestamp } \\
\hline 1 & EMERGENGY STOP & 2756 & 1211 Product no fuse \\
\hline 2 & MES CONNECTION & 2754 & 1213 Product fuse right \\
\hline 3 & MES CONNECTION & 2754 & 1213 Product fuse right \\
\hline 4 & EMERGENGY STOP & 2753 & 1211 Product no fuse \\
\hline 5 & MES CONNECTION & 2753 & 1211 Product no fuse \\
\hline 6 & EMERGENGY STOP & 2752 & 1214 Product both fuses \\
\hline 7 & EMERGENGY STOP & 2752 & 1214 Product both fuses \\
\hline & & & \\
\hline
\end{tabular}

d. Last errors

Figure 13. Drilling activity in the process model

\subsection{Solution 2 - Human Generated Information}

Solution two involved the creation of links between the drilling activity in the process model and external resources. Through the use of links, Uniform Resource Locator (URL), the following resources were made available: an online video demonstrating how the drilling module operates (Figure 14a), a student report stored in the university project database (Figure 14b), and a document with guidelines available on a shared document platform (Figure 14c).

\section{$5 \quad$ Findings}

This section evaluates the artifact and presents the feedback from the Lab manager. In the quotes, the squared brackets include clarifications from the authors. The reference architecture 
model contributed to the overall organizational learning process and to the information dissemination sub-process in four main ways. First, by providing the structure and the relations between equipment in the Lab as the following quote from the Lab manager shows: "something like this [the instantiation] would help me keep track of how things are connected, [... and] figuring out what exactly it is that I am looking for." In addition, the instantiation facilitated the explanation of the equipment in the Lab as the following quote shows: "it [the instantiation] is also a very nice way of communicating to other people, new people, [...] how it [the production line] works". Next, the models facilitated the management of information as the Lab manager pointed out: "it [the platform] provides the linking, the association between a certain student project or video [...] and a certain resource. [...] this [RAMI4.0] is effectively a way of collecting all the knowledge we have about the system [production line]." Finally, this instantiation can provide up-to-date information with the Lab manager as the following quote shows: "[this instantiation] is providing me with up to date information and all the relevant information."

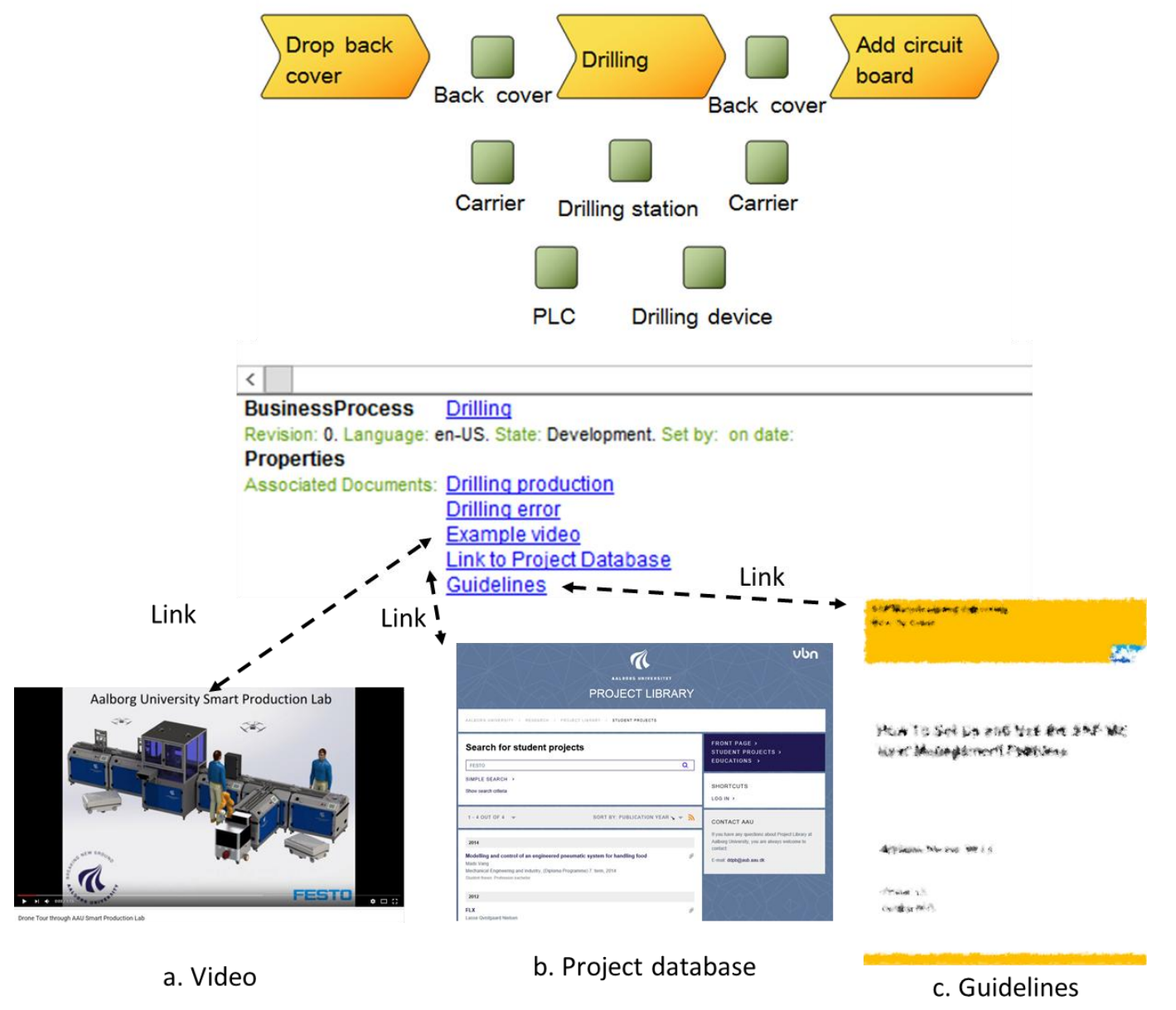

Figure 14. External resources linked to the model

Solution 1 was very valuable for reducing the response time in case of errors as the manager pointed out: "it [solution 1] can help me resolve the errors much faster because probably here [in the models] I can see what is making the error and what is the cause of the error".

Solution 2 supported information dissemination to new researchers as the following quote shows: "when training new people this [the instantiation] is a very valuable way. [...] It gives an overview what is actually the process of it [the production process]." Specifically, solution 2 enables sharing best-practices and safety information as the Lab manager pointed out: "You can click guidelines to know something about how I am supposed to use this one [the drilling module], what I can do, what I cannot do." Moreover, the link feature in solution 2 shares 
information in an intuitive way as the following quote shows: "If I have students [...] and I want them to work with something specific this [solution 2] is exactly how we could disseminate some of the information to them [students working in the Lab]. By simply providing them with easy access to the information".

This instantiation of RAMI4.0 was perceived by the Lab manager as very useful in order to support organizational learning and enable information dissemination. The way RAMI4.0 structures manufacturing information was positively perceived by the Lab manager. He found this structure easy to navigate and helpful to retrieve information related to the Lab. The two solutions were both found relevant and useful, and the platform used for the artifact reification was found appropriate, though no thorough alternatives analysis was made.

\section{Discussion}

To examine how RAMI4.0 can be used and instantiated, the authors used a design-science research approach, and designed as an artifact a model-based repository covering all the dimensions of reference architecture model. In this study, the models and the specific knowledge of the Lab was structured according to RAMI4.0, and the instantiation was from the beginning customized to this particular case.

Through the user research done with the artifact, the reference model contributed to organizational learning and to the information dissemination sub process, as reported above. Following the Lab manager's input, the existing instantiation will be extended to include all the main activities taking place at the Lab. In addition, more user research must be done to understand deeper this form of reification and participation in the organizational learning. The authors assessed that social learning theory will be useful when generalizing the concept of the Learning Factory.

The application of the reference architecture model to support the organizational learning process suggests that a reference model can be applied to structure information and support information dissemination and organizational learning. Providing a shared structure of information could most likely improve knowledge dissemination also outside the organization. Future research could investigate if a comprehensive model (not focused on the drilling activity) remains manageable and maintainable and therefore continue supporting organizational learning.

The advantage of using an enterprise architecture tool was that most of the functionalities required for this study were readily available. Most of the models used were fitting the requirements of RAMI4.0. The authors found particularly useful the features concerning the integration of data (e.g. error data) from external applications (e.g. MES system) to the models (e.g. Solution 1). For instance, it could be very useful to keep the model of the product with all its variants in the platform and have the MES system importing the details of the product (e.g. coordinates of the holes for the back cover) directly from the model. In this way, there would be only one and shared origin of the data.

The limitations of this study are to have analysed in detail only the drilling activity of the production line, to have not fully automated the integration between the models and the MES and ERP systems, and to have implemented the reference architecture model in a research laboratory and not in an industrial context. Another limitation is to have not performed an extensive evaluation of the artifact. Despite the mentioned limitations, this study presents solutions to common problems in the manufacturing industry an opens new research opportunities.

As next steps, the authors plan to apply RAMI4.0 in manufacturing companies to contribute with industrial cases. The work on developing artifacts for the Lab will also continue, and several new solutions will be added to the existing instantiation. Solution 1 will be extended with external integrations and status reporting in the models. This will take inspiration from "Business 
Operating System" [23] that defines five characteristics that are essential for situational awareness and operational intelligence: Destination, Map, Time, Decision, and Situation.

The new developments are likely to expand the scope and context that RAMI4.0 has. First, the architectural scope will be extended to encompass a fuller enterprise and ecosystem architecture, which is beyond the mainly technical scope of the reference architecture model. Second, other ways of assigning function models than the hierarchical thinking in levels and information system "zones" (ERP/MES/SCADA) that RAMI4.0 uses, will be evaluated, for instance much more decentralized control functions and integration solutions [24].

Consequently, further research must be done on foundation standards for the digital factory. A mapping of the standards landscape for smart manufacturing made by NIST [25] identified in over 100 standards, and several more have been developed since that study was made (published early 2016).

One of the most relevant new standards is the IEC Digital Factory Framework which is defined in the IEC 62832 series (Parts 1-3). The general principles (Part 1) have been available since December 2016. Part 2 on "Model elements" and Part 3 on "Application of Digital Factory for life cycle management of production systems" are still under development, expected to be published in 2018. The framework establishes a Digital Factory reference model and defines rules which govern the instantiation of assets and the establishment of links between the assets. This development is likely to influence how RAMI4.0s "administration shell" is further developed.

There are several other relevant standard developments going on, for instance the work around the architecture standards ISO42010, ISO42020 and ISO42030, as well as the work around ISO15704. There is ongoing revision work in ISO working groups, and updated and consolidated standards are expected in 2018.

It should also be noted that RAMI4.0 is often considered the "European" reference architecture for smart manufacturing, whereas the "North American" reference architecture is The Industrial Internet Reference Architecture (IIRA) "Technical Paper" [26] created and maintained by the Industrial Internet Consortium, an industry consortium owned by Object Management Group (OMG).

\section{Conclusion}

The new wave of industrial revolution addresses some of the key challenges in manufacturing industry. The instantiation of RAMI4.0 at the Learning Factory at Aalborg University demonstrated how reference architecture models contribute to organizational learning. The authors addressed the problem of information dissemination by enabling this process through the use of models. The solutions developed allowed to share in the research community selfgenerated and human generated information (e.g. respectively, machine errors and equipment guidelines). The reference model applied contributed to organizational learning by collecting relevant knowledge about a specific context (e.g. manufacturing equipment) and providing it when it is needed. In addition, RAMI4.0 reference model facilitated the management and explanation of the operations of the production line.

\section{References}

[1] International Electrotechnical Commission, "IEC PAS 63088:2017. Smart Manufacturing - Reference Architecture Model Industry 4.0 (RAMI4.0)," 2017.

[2] M. J. Tippins and R. S. Sohi, "IT competency and firm performance: Is organizational learning a missing link?," Strateg. Manag. J., vol. 24, no. 8, pp. 745-761, 2003. Available: https://doi.org/10.1002/smj.337

[3] S. F. Slater and J. Narver, "Market orientation and the learning organization," J. Mark., vol. 59, no. 3, pp. 63-74, 1995. Available: https://doi.org/10.2307/1252120 
[4] M. Nardello, C. Møller, and J. Gøtze, "The Industry 4.0 Journey: Start the Learning Journey with the Reference Architecture Model Industry 4.0," in CEUR Workshop Proceedings, 2017, vol. 1898, p. 11.

[5] R. Langmann and L. F. Rojas-Pena, "A PLC as an industry 4.0 component," in Proceedings of 201613 th International Conference on Remote Engineering and Virtual Instrumentation, REV 2016, 2016, pp. 10-15. Available: https://doi.org/10.1109/REV.2016.7444433

[6] F. Pauker, T. Fruehwirth, B. Kittl, W. Kastner, and T. Frühwirth, "A Systematic Approach to OPC UA Information Model Design," in Procedia CIRP, 2016, vol. 57, pp. 321-326. Available: https://doi.org/10.1016/j.procir.2016.11.056

[7] International Electrotechnical Commission, "IEC 62890 Life-cycle management for systems and products used in industrial-process measurement, control and automation,” 2016.

[8] T. J. Williams, "The Purdue Enterprise Reference Architecture, Technical Report 154," Purdue Lab. Appl. Ind. Control, 1991.

[9] P. Senge, “The fifth discipline: The art and science of the learning organization,” Doubleday, 1990.

[10] I. Nonaka, "The Knowledge-Creating Company," Harv. Bus. Rev., vol. 69, no. 6, pp. 96-104, 1991.

[11] C. Argyris and D. A. Schön, “Organizational Learning: A Theory of Action Perspective," Addison-Wesley, 1978.

[12] J. Lave and E. Wenger, "Situated learning: Legitimate peripheral participation," Cambridge Univ. Press, 1991. Available: https://doi.org/10.1017/CBO9780511815355

[13] J. S. Brown and P. Duguid, "Organizational learning and communities-of-practice: Toward a unified view of working, learning, and innovation," Organ. Sci., vol. 2, no. 1, pp. 40-57, 1991. Available: https://doi.org/10.1287/orsc.2.1.40

[14] E. Wenger, Communities of practice: Learning, meaning, and identity. Cambridge University Press, 1998. Available: https://doi.org/10.1017/CBO9780511803932

[15] E. C. Wenger and W. M. Snyder, "Communities of practice: The organizational frontier," Harv. Bus. Rev., vol. 78, no. 1, pp. 139-146, 2000.

[16] C. Moorman and A. S. Miner, "The impact of organizational memory on new product performance and creativity," J. Mark. Res., vol. 34, no. 1, pp. 91-106, 1997. Available: https://doi.org/10.2307/3152067

[17] G. Franco, P. Maresca, and G. Nota, "Modeling social influences in a knowledge management network," Int. J. Distance Educ. Technol., vol. 8, no. 1, pp. 1-16, 2010. Available: https://doi.org/10.4018/jdet.2010010101

[18] A. R. Hevner, S. T. March, J. Park, and S. Ram, "Design Science in Information Systems Research," MIS $Q .$, vol. 28, no. 1, pp. 75-105, 2004.

[19] K. Peffers, T. Tuunanen, M. A. Rothenberger, and S. Chatterjee, “A Design Science Research Methodology for Information Systems Research," Source J. Manag. Inf. Syst., vol. 24, no. 3, pp. 45-77, 2007. Available: https://doi.org/10.2753/MIS0742-1222240302

[20] QualiWare, "QualiWare Enterprise Architecture. Product/Platform Description.” [Online]. Available: https://www.qualiware.com/Enterprise-Architecture.

[21] A. Arsanjani, "Service-oriented modeling and architecture," IBM Dev. Work. whitepaper, p. 15, 2004.

[22] M. Nardello, O. Madsen, and C. Møller, "The Smart Production Laboratory: A Learning Factory for Industry 4.0 Concepts," in CEUR Workshop Proceedings, 2017, vol. 1898, p. 5.

[23] M. Kerremans and B. Robertson, "How a Business Operating System Can Guide CIOs to Digital Business Success.” Gartner Research, 2016.

[24] J. Hanson et al., "P2PIE: a New Enterprise Application Integration Solution 60-70," in CAiSE-2015 Industry Track co-located with 27th Conference on Advanced Information Systems Engineering (CAiSE 2015) Stockholm, Sweden, June 11, 2015, 2015, pp. 60-70.

[25] Y. Lu, K. C. Morris, and S. Frechette, "Current standards landscape for smart manufacturing systems," Natl. Inst. Stand. Technol. NISTIR, vol. 8107, 2016. Available: https://doi.org/10.6028/NIST.IR.8107

[26] Technology Working Group Industrial Internet Consortium, "IIC Architecture Task Group: The Industrial Internet Reference Architecture v1.8.” 2017. 